\title{
A Daytime Fast Track Improves Throughput in a Single Physician Coverage Emergency Department
}

\author{
Julie Copeland, MD*; Andrew Gray, MD*
}

\section{ABSTRACT}

Objectives: Fast tracks are one approach to reduce emergency department (ED) crowding. No studies have assessed the use of fast tracks in smaller hospitals with single physician coverage. Our study objective was to determine if implementation of an ED fast track in a single physician coverage setting would improve wait times for low-acuity patients without negatively impacting those of higher acuity. Methods: A daytime fast track opened in 2010 at Strathroy Middlesex General Hospital, a southwestern Ontario community hospital. Before and after intervention groups comprised of ED visits in 2009 and 2011 were compared. Pooled comparison of all Canadian Triage and Acuity Scale (CTAS) patients in each period, and between subgroups CTAS 2-5 comparisons were performed for: wait time (WT), length of stay (LOS), WTs that met national CTAS time guidelines (MNCTG), and proportion of patients that left without being seen (LWBS).

Results: WT and LOS were six minutes $(88 \mathrm{~min}$ to $82 \mathrm{~min}$, $p=0.002$ ) and 15 minutes $(158 \mathrm{~min}$ to $143 \mathrm{~min}, p<0.001$ ) lower, respectively, in the post-intervention period. Subgroup analysis showed CTAS 4 had the most pre- to postintervention decrease in WT, of 13 minutes $(98 \mathrm{~min}$ to $85 \mathrm{~min}$, $p<0.001)$. There was statistical improvement in MNCTG in the post-intervention period. No differences were found in outcome measures for higher-acuity patients or LWBS rates. Conclusions: Implementation of a fast track in a mediumvolume community hospital with single physician coverage can improve patient throughput by decreasing WT and LOS without negatively impacting high-acuity patients. This may be clinically relevant, particularly for hospital administrators, given the improvement in meeting national WT standards we found post-intervention.

\section{RÉSUMÉ}

Objectif: Le traitement accéléré des patients est un moyen de réduire l'encombrement des services des urgences (SU). Toutefois, aucune étude n'a porté sur le traitement accéléré des patients dans les petits hôpitaux où un seul médecin est de garde. L'étude visait à déterminer si la mise en œuvre du traitement accéléré des patients dans un SU où un seul médecin est de garde diminuerait les délais d'attente pour les patients souffrant de troubles peu graves, sans toutefois se répercuter défavorablement sur les patients se trouvant dans un état grave.

Méthode: Un processus de traitement accéléré des patients a été mis en œuvre, le jour, en 2010, au Strathroy Middlesex General Hospital, un hôpital communautaire situé dans le sud-ouest de I'Ontario. II y a eu comparaison des groupes de patients qui ont consulté au SU, en 2009 et en 2011, soit avant et après la mise en œuvre du traitement accéléré. Les auteurs ont procédé à des comparaisons globales de tous les patients, selon l'Échelle canadienne de triage et de gravité (ECTG) pour chaque période, ainsi qu'à des comparaisons partielles entre des sous-groupes de patients du $2^{\mathrm{e}}$ au $5^{\mathrm{e}}$ degré de priorité selon I'ECTG, en ce qui concerne les délais d'attente (DA), la durée de séjour (DS), le respect des lignes directrices nationales de I'ECTG au regard des DA et la proportion de patients qui sont partis sans avoir été examinés.

Résultats: Les DA et la DS ont été écourtés de 6 minutes $(88 \mathrm{~min}$ à $82 \mathrm{~min} ; p=0,002)$ et de 15 minutes $(158 \mathrm{~min}$ à $143 \mathrm{~min} ; p<0,001)$, respectivement, durant la période après I'intervention. Une analyse de sous-groupe a révélé que c'est dans le sous-groupe des patients du $4^{\mathrm{e}}$ niveau de priorité selon I'ECTG qu'a été enregistrée la diminution la plus importante des DA par rapport à la période avant l'intervention, soit 13 minutes $(98 \mathrm{~min}$ à $85 \mathrm{~min} ; p<0,001)$. Une amélioration statistiquement significative du respect des lignes directrices de I'ECTG a aussi été notée durant la période après l'intervention. Par contre, aucune différence n'a été relevée quant aux résultats cliniques observés chez les patients se trouvant dans un état grave ou encore quant aux taux de patients partis sans avoir été examinés.

Conclusions: La mise en œuvre du traitement accéléré dans un hôpital communautaire de capacité moyenne, où un seul médecin est de garde, peut accroître le débit des patients en diminuant les DA et la DS, sans toutefois se répercuter défavorablement sur les patients se trouvant dans un état grave. II s'agit là d'une mesure qui pourrait se révéler pertinente sur le plan clinique, particulièrement aux yeux des administrateurs d'hôpitaux, compte tenu de l'amélioration du respect des normes nationales sur les DA, constatée dans le groupe après l'intervention.

Keywords: fast track, emergency department, wait time

From the *Department of Family Medicine, Western University, London, ON

Correspondence to: Andrew Gray, 1810 Blackwater Road, London, ON, N5X 4J4; Email agray6@gmail.com

(C) Canadian Association of Emergency Physicians 2015 CJEM 2015;17(6):648-655

DOI 10.1017/cem.2015.41 


\section{INTRODUCTION}

The Canadian Association of Emergency Physicians (CAEP) recently published their third position statement in 20 years expressing concern over emergency department (ED) crowding. ${ }^{1}$ In 2012, Canada was rated worst among 11 developed countries for patients waiting longer than four hours to be seen in the ED. ${ }^{2}$ A recent international survey found more Canadians wait longer than six days to see their family doctor than in any of the aforementioned countries, ${ }^{3}$ a situation that likely contributes to ED crowding.

One approach to decrease ED crowding is a fast track (FT). ${ }^{4}$ The concept is based on the "lean thinking theory, ${ }^{, 5} 6$ and involves implementation of a separate patient stream where low-acuity and low-complexity patients are treated in a defined area. ${ }^{7}$ Often this involves dedicated beds or chairs and a separate waiting room. Previous studies have shown that FTs can decrease wait times, length of stay (LOS), and crowding in tertiary care centers. $^{4,7-9}$ There is also evidence indicating that FTs do not negatively impact higher-acuity patients. ${ }^{10-13}$ However, there have been few studies to evaluate FTs in Canadian settings. Moreover, many FT studies are potentially confounded by simultaneous increases in either total physician and nursing hours or ED beds. More staff or space has a financial cost that may not be feasible depending on the setting involved. As a result, there is a paucity of strong evidence for or against FT implementation in community hospitals. ${ }^{1}$ This study was designed to determine if FTs are an effective strategy to reduce wait times in a single physician coverage ED. Our hypothesis was that patient throughput after FT implementation would improve for low-acuity patients (Canadian Triage and Acuity Scale [CTAS] 4-5), without negatively impacting the care of higher-acuity patients (CTAS 2-3).

\section{METHODS}

\section{Design and setting}

A retrospective cohort study of patients presenting to Strathroy Middlesex General Hospital (SMGH) in the year before and after implementation of a FT was undertaken. SMGH is a 54-bed community-based teaching hospital in southwestern Ontario, and serves a population of approximately 35,000 people. The hospital has a census of approximately 25,000 emergency visits per year, $24 \%$ of which are pediatric ( $<18$ years), and is categorized as a medium-volume hospital according to the Ontario Ministry of Health and Long-Term Care. ${ }^{14}$

The ED of SMGH is staffed predominately by a single family physicians. Physicians work shifts of 0700-1500 hrs, $1400-2200 \mathrm{hrs,} \mathrm{and} \mathrm{2100-0700} \mathrm{hrs,}$ resulting in two hours of overlapping coverage during handover and a total of 26 physician work hours per day. Nursing shifts from 0700-1900 hrs and 1900-0700 hrs are staffed by three nurses, while one additional nurse provides coverage during peak hours of $1100-2300 \mathrm{hrs}$, for a total of 84 nurse work hours per day.

\section{Intervention}

A fast track (FT) was launched at SMGH in June 2010, consisting of a reallocation of existing resources; there was no physical space or equipment added. There were 14 assessment areas before the intervention, and one additional room after restructuring, comprised of a room that was previously used for other needs, which was converted into the new chair-only assessment area. There were no additional nursing or physician hours after the intervention; one of the usual three to four nurses on staff was repatriated to FT during hours of operation, and provided care only to these patients.

From $2100-0900 \mathrm{hrs}$ there were no department changes; patient flow proceeded as it had before, with the exception of the additional chair room mentioned earlier. From 0900-2100 hrs, FT was considered “open.” During this time, five of 15 assessment areas that were previously part of the acute area became dedicated to FT, including the new chair room. All FT rooms were physically adjacent to one another and separate from patients in acute care beds, effectively creating a physical area in the department comprised only of FT patients called "Green Zone" (Figure 1). Our FT included a number of chairs in the hallway outside FT rooms to function as a waiting area for patients in that zone.

The intervention under study was a change in patient flow in the ED and its effect on throughput. Upon presentation, patients were triaged either to regular acute beds or the FT. Experienced triage nurses were provided additional training on selecting patients for the FT based on the complexity of patient complaints, and applying the lean thinking theory in a manner consistent with previous studies. ${ }^{6,7}$ FT patients were generally ambulatory, CTAS 4-5, and had straightforward presenting complaints deemed by the triage nurse to likely require few 


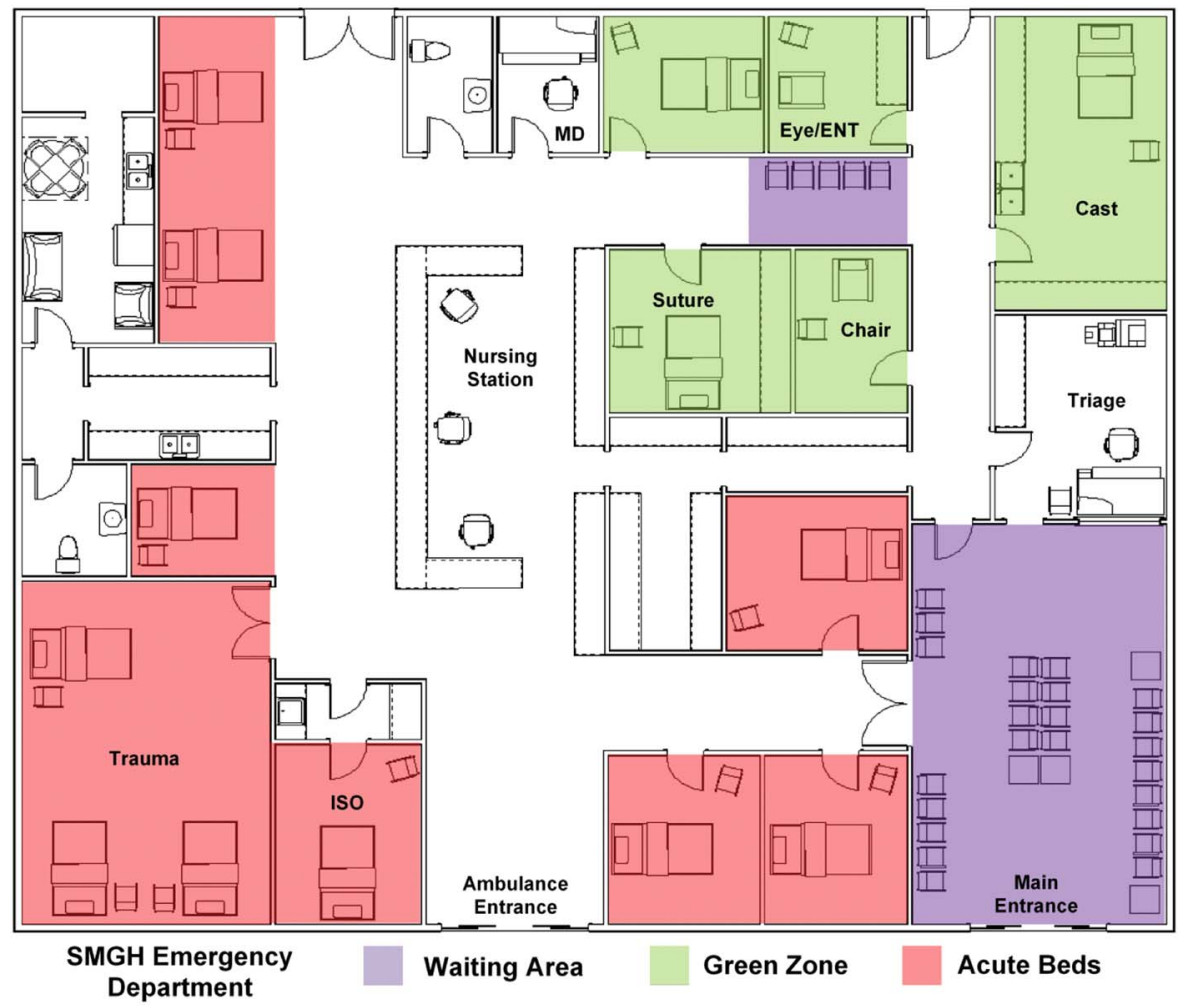

Figure 1. Emergency Department layout showing Fast Track (Green Zone) area. SMGH-Strathroy Middlesex General Hospital

investigations and a disposition of discharge home. CTAS 1-2 patients were excluded from the FT. Physicians were expected to flow between the acute area and the FT, following some general rules. First, high-acuity patients were assessed in the acute area, in keeping with national CTAS time guidelines. ${ }^{15}$ Once nurses had queued a number of FT patients into rooms waiting to be seen, the physician would go down the hallway to the FT area to assess and treat a number these patients sequentially. Generally, these patients had lower CTAS scores than others still waiting to be seen in the acute area, and often they had been waiting for less time. Following this, the physician would return to the acute area to manage high-acuity patients until the cycle was repeated.

\section{Time period}

Study periods chosen to represent before and after the intervention ended and started approximately six months from the intervention date. This time gap was utilized in part to allow each group to fall into only one calendar year, but also to provide a wash-out period surrounding the intervention date. Matched one-year study periods were chosen to control for the effects of seasonal variation and any imbalance between study groups that could arise from this, for example from higher patient volumes in the winter. To be sure that study groups were matched for time and evenly distributed throughout the year, the first seven days of all 12 months were included in each group, for a resulting total of 84 days in both the before and after periods. We chose this representative sample of each time period to avoid an overwhelming sample size and the resulting increased workload that would be required for data analysis. The before intervention group included patients from the days in 2009 mentioned earlier; the after intervention group included those in 2011.

\section{Inclusion and exclusion criteria}

Patients of all CTAS levels triaged at SMGH ED during FT hours of operation (9 a.m. to 9 p.m.) during the time periods of the study were eligible for enrollment. Patients were excluded if they had incomplete or incorrect charts, defined as any of the following: 1) disposition coded as assessed by physician 
with no assessment time noted; 2) disposition coded as not assessed by a physician, but an assessment time was recorded in error; 3) assessment time earlier than triage time, causing a negative wait time; 4) missing demographic information such as age or gender.

\section{Outcome measures and calculations}

The two primary outcomes for patient throughput were wait time (WT) and length of stay (LOS). Secondary outcomes were the proportion of WTs that met national CTAS time guidelines (MNCTG) and the proportion of patients that left without being seen (LWBS). In 1998, CAEP published national hospital WT standards, advising that each ED patient be assessed by a physician according to their CTAS. ${ }^{15}$ These guidelines deem that CTAS 1 patients should be assessed immediately by the physician, CTAS 2 within 15 minutes, and CTAS 3, 4, and 5 within 30, 60, and 120 minutes, respectively. We deemed a priori that a clinically significant change in WT is one with an impact significant enough to have more patients be seen within the national CTAS time guidelines. Our other secondary outcome, LWBS, has been proposed in previous studies to be a marker of crowding. ${ }^{10,16}$

\section{Data collection}

The hospital electronic medical record system was utilized to create a database of visits during the study periods that included the following information: hospital identification number, age, gender, CTAS level, date and time triaged, date and time of first physician assessment, date and time of disposition, disposition code, and discharge diagnosis code.

FT status was not included on the hospital electronic medical record system, so a random number generator was used to select three days included in our "after" study period, for which all charts were reviewed to calculate the average patient flow through the FT. A total of 149 charts were reviewed by the primary researcher, and the following information was recorded: date of visit, CTAS level, and whether patient was seen in the FT or acute area.

\section{Statistical analysis}

Continuous variables (WT and LOS) were first tested for normality of distribution using the KolmogorovSmirnov test. Outcome measures were compared between groups using the Mann-Whitney U-test for non-normally distributed continuous variables, or Student t-test for normally distribution continuous variables. Nominal variables (MNCTG and LWBS) were compared between groups using the chi-square test, or Fisher exact test in the case of infrequent occurrences $(<10)$. Descriptive statistics were reported for non-parametric continuous variables as median with interquartile range (IQR), and for parametric continuous variables as mean with standard deviation (SD). Nominal variables were reported as frequencies with percentage. All tests were considered significant at $p$ value $<0.05$. Statistical analysis was done using SPSS Statistics (IBM, Version 21).

\section{Subgroup analysis}

Analyses of outcome measures were repeated within four a priori subgroups. Each subgroup consisted of the same patients as above, categorized by CTAS levels 2 through 5 . The purpose of subgroup analysis was to determine, if an overall improvement in outcome measures was achieved across all CTAS levels, whether this significantly impacted any outcome measures within any individual levels. CTAS 1 cases were not included, as it was assumed implementation of a FT should have no impact on these cases, since they are seen immediately.

\section{Ethics}

The study was approved by both the University of Western Ontario Research Ethics Board for Health Sciences Research Involving Human Subjects, and the Strathroy Middlesex General Hospital Research Committee.

\section{RESULTS}

A total of 7,432 ED visits met inclusion criteria; 3,670 before and 3,762 after, with 95 and 33 charts being excluded in each time period respectively. Demographic characteristics of the study participants in the before and after groups were similar (Table 1). A similar distribution of the most frequent problems between the two groups was also seen (Table 2).

The chart review indicated that $43 \%$ (64 of 149) of patients flowed through the FT during its hours of operation. Of those, $84 \%$ (54 of 64) were CTAS 4, a much higher proportion than seen in the acute area. 


\begin{tabular}{|c|c|c|}
\hline & Before Group (2009) & After Group (2011) \\
\hline No. of Patient visits & 3,575 & 3,729 \\
\hline Age (median [IQR]) & 38 [18-59] & 40 [19-62] \\
\hline \multicolumn{3}{|l|}{ GENDER } \\
\hline Male & $47.6 \%[1,702]$ & $47.9 \%[1,785]$ \\
\hline Female & $52.4 \%[1,873]$ & $52.1 \%[1,944]$ \\
\hline \multicolumn{3}{|l|}{ CTAS } \\
\hline 1 & $0.3 \%[11]$ & $0.1 \%[5]$ \\
\hline 2 & $7.5 \%$ [269] & $6.7 \%[251]$ \\
\hline 3 & $39.5 \%[1,413]$ & $36.8 \%[1,374]$ \\
\hline 4 & $50.8 \%[1,816]$ & $54.8 \%[2,042]$ \\
\hline 5 & $1.8 \%[66]$ & $1.5 \%[57]$ \\
\hline \multicolumn{3}{|l|}{ DISPOSITION } \\
\hline Admitted & $5.9 \%[211]$ & $6.0 \%[224]$ \\
\hline Discharged & $88.1 \%[3,151]$ & $87.6 \%[3,268]$ \\
\hline
\end{tabular}

Table 2. Top 10 most common coded disposition diagnoses for the study groups.

\begin{tabular}{lll} 
& Before Group (2009) & After Group (2011) \\
\hline Most common & Acute URTI & Acute URTI \\
& UTI & Abdominal pain \\
& Abdominal pain & UTI \\
& Pneumonia & Pneumonia \\
& Chest pain & AOM \\
& Finger laceration & Ankle sprain \\
& AOM & Chest pain \\
& Ankle sprain & Gastroenteritis/colitis \\
& Low back pain & Strep pharyngitis \\
Least common & Acute pharyngitis & Finger laceration \\
\hline $\begin{array}{l}\text { URTI: upper respiratory tract infection } \\
\text { UTI: urinary tract infection } \\
\text { AOM: acute otitis media }\end{array}$ & \\
\hline
\end{tabular}

Table 3 shows the primary and secondary outcomes for the study groups. The median WT decreased by six minutes after implementation of a FT $(p=0.002)$. The median LOS decreased by 15 minutes $(p<0.001)$ after implementation of a FT, and there was an absolute improvement of $3.6 \%$ in MNCTG $(p<0.001)$. No difference was found in LWBS proportions before and after the intervention ( $4.6 \%$ to $4.4 \%$, respectively; $p=0.738)$.

CTAS subgroup analysis indicated that only CTAS 4 patients had a significant change after the intervention. Higher levels (CTAS 2-3) were not negatively impacted for any of the primary or secondary study outcomes. Table 4 shows primary and secondary outcomes, categorized by CTAS level, for the study groups. The result trends of the CTAS 4 subgroup analysis matched those for the entire population, with the difference that the changes were more dramatic: WT decreased by 13 minutes $(p<0.001)$ and LOS by 22 minutes $(p<0.001)$ in the CTAS 4 group, while the MNCTG increased by $5.3 \%(p=0.001)$.

\section{DISCUSSION}

Our results suggest that the addition of a FT can improve ED crowding by significantly decreasing WT and LOS, a finding consistent with similar studies in tertiary care settings. ${ }^{8-10}$ However, our study results suggests two important features that previous work has not investigated: 1) increased throughput can be accomplished even in a single physician ED; and 2) increased throughput can be accomplished even when no additional staff are added in the restructuring process. The FT restructuring at our study location

Table 3. Primary and secondary outcomes in the study groups.

\begin{tabular}{lccc} 
& Before Group (2009) & After Group (2011) & $p=0.002$ \\
\hline Median WT & $88[48-143]$ & $82[44-143]$ & $\mathrm{n}=3,564$ \\
(minutes [IQR]) & $\mathrm{n}=3,411$ & $143[88-218.5]$ & $p<0.001$ \\
Median LOS & $158[100-230]$ & $\mathrm{n}=3,729$ & $p=0.738$ \\
(minutes [IQR]) & $\mathrm{n}=3,575$ & $4.4 \%[165]$ & $p<0.001$ \\
LWBS & $4.6 \%[164]$ & $25.0 \%[891]$ & \\
MNCTG & $21.4 \%[727]$ & & \\
WT: wait time & & \\
LOS: length of stay & & \\
MNCTG: met national CTAS (Canadian Triage and Acuity Scale) time guidelines & & \\
LWBS: left without being seen & &
\end{tabular}


Fast track improves throughput in a single physician emergency department

\begin{tabular}{|c|c|c|c|}
\hline & Before Group (2009) & After Group (2011) & $p$ value \\
\hline \multicolumn{4}{|l|}{ CTAS 2} \\
\hline Median WT & $40[21.75-74]$ & $40[23-77]$ & $=0.904$ \\
\hline (minutes [IQR]) & $n=266$ & $n=249$ & \\
\hline Median LOS & 189 [120-273.5] & 185 [118-253] & $=0.210$ \\
\hline (minutes [IQR]) & $n=269$ & $n=251$ & \\
\hline LWBS & $1.1 \%[3]$ & $0.8 \%[2]$ & $=1.000$ \\
\hline MNCTG & $15.4 \%[41]$ & $17.7 \%[44]$ & $=0.490$ \\
\hline \multicolumn{4}{|l|}{ CTAS 3} \\
\hline Median WT & 86 [50-139.5] & 87 [49-140] & $=0.538$ \\
\hline (minutes [IQR]) & $n=1,365$ & $n=1,330$ & \\
\hline Median LOS & 175 [117-250] & 186 [117.75-262] & $=0.153$ \\
\hline (minutes [IQR]) & $n=1,413$ & $n=1,374$ & \\
\hline LWBS & $3.4 \%[48]$ & $3.2 \%[44]$ & $=0.774$ \\
\hline MNCTG & $11.9 \%[162]$ & $11.8 \%[157]$ & $=0.959$ \\
\hline \multicolumn{4}{|l|}{ CTAS 4} \\
\hline Median WT & 98 [57-157] & 85 [47-135] & $<0.001 *$ \\
\hline (minutes [IQR]) & $n=1,711$ & $n=1,926$ & \\
\hline Median LOS & $140[90-210]$ & 118 [78-178.5] & $<0.001^{*}$ \\
\hline (minutes [IQR]) & $n=1,816$ & $n=2,042$ & \\
\hline LWBS & $5.8 \%[105]$ & $5.7 \%[116]$ & $=0.893$ \\
\hline MNCTG & $28.2 \%[482]$ & $33.5 \%[645]$ & $=0.001^{*}$ \\
\hline \multicolumn{4}{|l|}{ CTAS 5} \\
\hline Median WT & 64.5 [26.5-126.5] & 58.5 [20-106.75] & $=0.403$ \\
\hline (minutes [IQR]) & $n=58$ & $n=54$ & \\
\hline Median LOS & 101.5 [48.5-163.75] & 95 [42-120.5] & $=0.173$ \\
\hline (minutes [IQR]) & $n=66$ & $n=57$ & \\
\hline LWBS & $12.1 \%[8]$ & $5.3 \%[3]$ & $=0.219$ \\
\hline MNCTG & $72.4 \%[42]$ & $83.3 \%[45]$ & $=0.166$ \\
\hline \multicolumn{4}{|c|}{$\begin{array}{l}\text { WT: wait time } \\
\text { LOS: length of stay } \\
\text { MNCTG: met national CTAS (Canadian Triage and Acuity Scale) time guidelines } \\
\text { LWBS: left without being seen } \\
\text { IQR: interquartile range } \\
\text { "statistically significant at } p \leq 0.05 \text { threshold }\end{array}$} \\
\hline
\end{tabular}

involved little change in resources and no additional physical space, but rather simply a change in patient and staff flow. Although the intervention was only found to result in statistically significant changes for CTAS 4 patients on subgroup analysis, it merits consideration that CTAS 4 makes up over $50 \%$ of our ED visits, a proportion similar to other low-acuity community EDs across the country. Moreover, the improvements we found in $\mathrm{ED}$ metrics occurred in spite of an overall increase in volume of $1.7 \%$ (from 22,950 visits in 2009, to 23,335 in 2011).

The ability to improve throughput with no additional resources may be explained in part by improved physician efficiency. Rather than traveling in an unstructured manner throughout the ED based on a global queue, physicians managed batches of patients in the FT, ordered labs and imaging simultaneously on those patients, and returned later only when a number of patients could be reassessed, thus reducing travel time from one end of the department to the other. This is consistent with the lean thinking theory, which suggests it is inherently more efficient to serve batches of quick customers to reduce crowding. ${ }^{5,6}$

We did not find a decrease in number of patients LWBS after the intervention, a finding in contrast to other studies, ${ }^{1,7-11,16}$ even in subgroup analysis where the WT decrease was most dramatic. Thus an important question remains: does a decrease in WT of between six and 13 minutes result in a change in crowding that patients notice or deem to be significant? Previous studies have suggested that improvement in LWBS is related to patient satisfaction. ${ }^{1,10,16,17}$ 
It is possible that our study failed to show a clinically significant change for this metric due to an already low proportion of patients that LWBS at our hospital before the intervention $(<5 \%)$. In addition, LWBS may not be the only indicator of patient satisfaction; two prior studies have indicated that the most important factor determining satisfaction is decreasing WT. ${ }^{18,19}$ While we cannot come to a definitive conclusion about patient satisfaction, we believe that the decrease found in WT in our study is still clinically relevant, since it was associated with an improvement in meeting the national CTAS time guidelines. This relevance was underscored by a recent CAEP position statement suggesting that implementing and improving national WT benchmarks is an essential component of initiatives to improve ED crowding. ${ }^{1}$ It is noteworthy that the increase in MNCTG we found for CTAS 4 patients $(5.3 \%)$, and the obvious trending increase for CTAS 5 patients (10.9\%), occurred without CTAS 2-3 patients suffering any detrimental effects, as measured by any of our primary or secondary outcomes. The significant improvement in MNCTG may be of particular importance to hospital administrators seeking to improve benchmark performance.

\section{LIMITATIONS}

Several limitations should be considered when interpreting our results. Our study was limited by the fact that it was a single-center retrospective observational study. Data collection was not blinded; however, the observers who recorded the original chart data were not aware of this study at that time. Our design relied upon accurate observations and transcriptions, and thus is subject to human error. We believed any small positive or negative errors in recording or transcribing times would balance out across our sample, and made efforts to remove gross errors through our exclusion criteria. Although no a priori calculation was done, we feel the study sample size of over 7,000 provided sufficient power for a study of this nature. It could be argued, however, that another limitation is that we only included a representative sample of each study period rather than every day of the year. Finally, patient-oriented health outcomes, in particular morbidity or mortality, were not evaluated; however, previous studies with a similar design have found no impact on either of these. ${ }^{8,9}$

One possible confounder to consider is that family medicine resident work hours increased by approximately three hours per day from the before to the after period (nine hours per day before and 12 hours per day after FT implementation). This was not related to FT restructuring. It is possible that this increase could account for some the decrease in WT. However, the increase in coverage is rather small $(<3 \%$ increase of total daily staff hours), so we feel that any effect from this would likely be minor. It should also be considered that, in contrast to attending staff, increase in resident hours leads to increased clinical teaching time, which may in fact increase WT.

An additional possible confounder to consider is that the addition of one assessment area (chair-only room) after the intervention may have accounted for some of the decrease in WT we observed. Unlike some tertiary care hospitals, we designed this study based on the assumption that the WT bottleneck in smaller community hospitals lies with the physician rather than the number of beds available, especially in a single physician department. Regardless, the impact of this one-chair increase was rather small, from 14 to 15 assessment areas (an increase of approximately 7\%).

\section{CONCLUSIONS}

Implementation of a fast track in a medium-volume community hospital with single physician coverage can improve patient throughput by decreasing WT and LOS without negatively impacting high-acuity patients. Our results illustrate that this can be accomplished without an increase in physician or nursing hours, and with minimal change in ED space and resources. It is uncertain whether patients notice the decrease in crowding, but the increased throughput may be particularly relevant for hospital administrators wishing to improve benchmark standards.

Competing Interests: None to declare.

\section{REFERENCES}

1. Affleck A, Parks P, Drummond A, et al. Emergency department overcrowding and access block. CFEM 2013; 15(6):359-70, doi:10.2310/8000.CAEPPS.

2. Canadian Institute for Health Information. Health care in Canada, 2012: A focus on wait times. Canada: November 29, 2012. Available at: https://secure.cihi.ca/free_products/ HCIC2012-FullReport-ENweb.pdf (accessed May 22, 2013).

3. Schoen C, Osborn R, Squires D, et al. Access, affordability, and insurance complexity are often worse in the United States 
compared to ten other countries. Health Aff 2013; 32(12):2205-15, doi:10.1377/hlthaff.2013.0879.

4. Yoon P. Emergency department fast-track system. HTA Initiative \#10. Edmonton (AB): Alberta Heritage Foundation for Medical Research; 2003.

5. King DL, Ben-Tovim DI, Bassham J. Redesigning emergency department patient flows: application of lean thinking theory to health care. Emerg Med Australas 2006;18(4): 391-7.

6. Dickson EW, Anguelov Z, Vetterick D, et al. Use of lean in the emergency department: a case series of 4 hospitals. Ann Emerg Med 2009;54(4):504-10, doi:10.1016/j. annemergmed.2009.03.024.

7. Ieraci S, Digiusto E, Sonntag P, et al. Streaming by case complexity: Evaluation of a model for emergency department Fast Track. Emerg Med Australas 2008;20(3):241-9, doi:10.1111/j.1742-6723.2008.01087.x.

8. Sanchez M, Smally AJ, Grant RJ, et al. Effects of a fast-track area on emergency department performance. 7 Emerg Med 2006;31(1):117-20.

9. Devkaran S, Parsons H, Van Dyke M, et al. The impact of a fast track area on quality and effectiveness outcomes: A Middle Eastern emergency department perspective. $B M C$ Emerg Med 2009;9:11, doi:10.1186/1471-227X-9-11.

10. Darrab AA, Fan J, Fernandes CM. How does fast track affect quality of care in the emergency department? Eur $\mathcal{Z}$ Emerg Med 2006;13(1):32-5.

11. O'Brien D, Williams A, Blondell K, et al. Impact of streaming "fast-track" emergency department patients. Aust Health Rev 2006;30(4):525-32.
12. Cooke MW, Wilson S, Pearson S. The effect of a separate stream for minor injuries on accident \& emergency waiting times. Emerg Med 7 2002;19(1):28-30.

13. Kwa P, Blake D. Fast track: Has it changed patient care in the emergency department? Emerg Med Australas 2008;20(1):10-15.

14. Ontario Ministry of Health and Long-Term Care. Ontario wait times: Time spent in the ER - About the data. Canada: June 21, 2011. Available at: http://www.health.gov.on.ca/ en/pro/programs/waittimes/edrs/about_ts.aspx\#1 (accessed May 22, 2013).

15. Canadian Association of Emergency Physicians. Implementation guidelines for the Canadian emergency department triage and acuity scale. Canada: December 16, 1998. Available at: http://caep.ca/resources/ctas/implementationguidelines (accessed May 22, 2013).

16. Fernandes CM, Price A, Christenson JM. Does reduced length of stay decrease the number of emergency department patients who leave without seeing a physician? 7 Emerg Med 1997;15(3):397-9.

17. Fernandes CM, Daya MR, Barry S, et al. Emergency department patients who leave without seeing a physician: The Toronto hospital experience. Ann Emerg Med 1994; 24(6):1092-6.

18. Dinh MM, Enright N, Walker A, et al. Determinants of patient satisfaction in an Australian emergency department fast-track setting. Emerg Med 7 2012;epub,1-4, doi:10.1136/ emermed-2012-201711.

19. Bursch B, Beezy J, Shaw R. Emergency department satisfaction: What matters most? Ann Emerg Med 1993;22(3): 586-91. 